\title{
Sulforaphane-cysteine suppresses invasion via downregulation of galectin-1 in human prostate cancer DU145 and PC3 cells
}

\author{
HUA TIAN $^{1}$, YAN ZHOU ${ }^{1}$, GAOXIANG YANG $^{1}$, YANG GENG $^{1}$, SAI WU $^{1}$, \\ YABIN HU ${ }^{1}$, KAI LIN ${ }^{1}$ and WEI WU ${ }^{1,2}$ \\ ${ }^{1}$ Department of Biochemistry and Molecular Biology, School of Basic Medical Sciences, Capital Medical University; \\ ${ }^{2}$ Institute of Brain Tumor, Beijing Institute for Brain Disorders, Capital Medical University, Beijing 100069, P.R. China
}

Received February 16, 2016; Accepted March 17, 2016

DOI: $10.3892 /$ or.2016.4942

\begin{abstract}
Our previous study showed that sulforaphane (SFN) inhibits invasion in human prostate cancer DU145 cells; however, the underlying mechanisms were not profoundly investigated. In the present study, we found that sulforaphane-cysteine (SFN-Cys), as a metabolite of SFN, inhibits invasion and possesses a novel mechanism in prostate cancer DU145 and PC3 cells. The scratch and Transwell assays showed that SFN-Cys $(15 \mu \mathrm{M})$ inhibited both migration and invasion, with cell morphological changes, such as cell shrinkage and pseudopodia shortening. The cell proliferation (MTS) assay indicated that cell viability was markedly suppressed with increasing concentrations of SFN-Cys. Furthermore, the Transwell assay showed that inhibition of SFN-Cys-triggered invasion was tightly linked to the sustained extracellular signal-regulated kinase 1/2 (ERK1/2) phosphorylation. Western blot analysis revealed that SFN-Cys downregulated galectin-1 protein, an invasion-related protein, and that the galectin-1 reduction could be blocked by ERK1/2 inhibitor PD98059 (25 $\mu \mathrm{M})$. Moreover, immunofluorescence staining showed that the expression level of galectin-1 protein was significantly reduced in the cells treated with SFN-Cys. Hence, SFN-Cys-inhibited invasion resulted from the sustained ERK1/2 phosphorylation and ERK1/2-triggered galectin-1 downregulation, suggesting that galectin-1 is a new SFN-Cys target inhibiting invasion apart from ERK1/2, in the treatment of prostate cancer.
\end{abstract}

\section{Introduction}

The mortality rate of prostate cancer has greatly increased globally in recent years, due to the fact that this type of

Correspondence to: Professor Wei Wu, Department of Biochemistry and Molecular Biology, School of Basic Medical Sciences, Capital Medical University, 10 Xitoutiao, You An Men Wai Avenue, Feng Tai, Beijing 100069, P.R. China

E-mail: weiwu207@ccmu.edu.cn

Key words: sulforaphane-cysteine, extracellular signal-regulated kinase $1 / 2$, galectin-1, invasion, prostate cancer tumor is not easily detected. Owing to its lack of noticeable symptoms, prostate cancer is commonly ignored. Once it is diagnosed, the tumor has usually invaded other tissues or organs and has undergone metastasis. It is essential to find a satisfactory strategy by which to treat prostate cancer, because to date traditional therapies applied including surgery, radiotherapy, chemotherapy and comprehensive therapy have not been effective in treating this disease. The reason is that these methods do not inhibit invasion and metastasis, thus the development of a new drug to suppress invasion and metastasis is the key for clinical treatment.

Epidemiological studies have shown that cruciferous vegetables reduce the risk of a variety of cancers (1). Sulforaphane (SFN), as an isothiocyanate, effectively inhibits the growth of various tumor cells (2). SFN metabolizes and generates metabolites such as sulforaphane-glutathione (SFN-GSH), sulforaphane-cysteine-glycine (SFN-CG), sulforaphane-cysteine (SFN-Cys), and sulforaphane- $N$-acetylcysteine (SFN-NAC). SFN metabolites may be the main compounds in tissues, rather than SFN (3). The metabolites, especially SFN-Cys, were found to inhibit histone deacetylase (HDAC) activity and have a higher plasma concentration and longer half-life $(4,5)$, which may contribute to cancer inhibition. Our previous studies showed that SFN inhibited invasion through phosphorylation of extracellular signal-regulated kinase 1/2 (ERK1/2) and CD44v6 downregulation in human prostate cancer DU145 cells (6). However, the key mechanisms of SFN-Cys in the inhibition of prostate cancer migration and invasion are not yet clear.

ERK1/2 are members of the mitogen-activated protein kinase (MAPK) family, which can be activated by various extracellular stimuli. ERK1/2 phosphorylation regulates the activation of downstream substrate molecules (7) and mediates signal transduction processes in many cancer cells. Sustained ERK1/2 phosphorylation was found to inhibit growth and invasion, and induce cell cycle arrest and apoptosis (8-11). Transient $(<15 \mathrm{~min})$ ERK1/2 phosphorylation was found to contribute to cancer proliferation and invasion $(12,13)$. Further studies to find out the downstream signaling molecules are necessary for an overview of the whole signaling cascade.

Galectins are a $\beta$-galactoside-binding protein family, consisting of 15 members. It was reported that the expression level of galectin-1 is increased in various tumor cells 
including hepatocellular carcinoma (14), pancreatic ductal adenocarcinoma (15), oral squamous cell carcinoma (16), vulvar neoplasia (17) and colorectal cancer (18). Knockdown of galectin-1 through small interfering RNA in highly invasive cancer cells reduced invasion. Moreover, the invasion levels in poorly invasive cancer cells were significantly increased after overexpression of galectin-1 (19). Galectin-1 is involved in cell-to-cell, cell-to-extracellular matrix (ECM) adhesion and aggregation (20). Furthermore, transient activation of ERK1/2 contributed to galectin-1 increase, and the high expression of galectin-1 was reversed by the ERK1/2 inhibitor U0126 in T lymphocytes (21). Therefore, sustained ERK1/2 phosphorylation may lead to galectin-1 downregulation in human prostate cancer cells. The possible mechanisms of galectin-1 that contribute to cancer invasion need to be further investigated and discussed.

In the present study, we investigated the effects of SFN-Cys on prostate cancer cell proliferation, invasion and the underlying mechanisms, which will help us identify more targets and provide a basis for the clinical application of SFN-Cys in the treatment of prostate cancer.

\section{Materials and methods}

Reagents. D,L-sulforaphane-L-cysteine (SFN-Cys) and the anti-galectin-1 antibody were purchased from Santa Cruz Biotechnology (Santa Cruz, CA, USA). Dimethyl sulfoxide (DMSO) was acquired from AppliChem $\mathrm{GmbH}$ (Darmstadt, Germany). RPMI-1640 culture medium was purchased from HyClone (Logan, UT, USA). Fetal bovine serum (FBS) and penicillin-streptomycin were obtained from Invitrogen (Carlsbad, CA, USA). $\beta$-actin antibody was purchased from ProteinTech Group, Inc. (Chicago, IL, USA). The phosphorylated ERK1/2 (pERK1/2), ERK1/2 and ERK1/2 inhibitor (PD98059) were obtained from Cell Signaling Technology, Inc. (Shanghai, China). The MTS assay kit was purchased from Promega (Madison, WI, USA). Transwell plates and Matrigel basement membrane matrix for invasion assay were obtained from BD Biosciences (Bedford, MA, USA). The DAPI staining solution was purchased from Beyotime Institute of Biotechnology (Nantong, China).

Cell culture. Human prostate cancer cell lines DU145 and PC3 were purchased from the Cell Resource Center, Peking Union Medical College (CRC/PUMC). Cells were cultured in RPMI-1640 medium with $10 \% \mathrm{FBS}, 100 \mathrm{U} / \mathrm{ml}$ penicillin and streptomycin. The cells were maintained at $37^{\circ} \mathrm{C}$ in a humidified incubator containing $5 \% \mathrm{CO}_{2}$.

Cell morphology. DU145 and PC3 cells at $80 \%$ confluency were exposed to SFN-Cys at different concentrations $(0,5$, 10 , and $15 \mu \mathrm{M})$ for $24 \mathrm{~h}$ in 6 -well plates. Cell morphology was observed with phase contrast microscope at x100 magnification (Leica, Germany). Digital cameras recorded the morphological change of the prostate cancer cells.

MTS assay. The cell viability was determined using the MTS assay kit (Promega). The cells $\left(4-6 \times 10^{3}\right)$ were seeded in 96-well plates and treated with various doses of SFN-Cys for $24 \mathrm{~h}$. Then $20 \mu \mathrm{l}$ of MTS reagent was added to each well and incubated at $37^{\circ} \mathrm{C}$ for $1 \mathrm{~h}$. The absorbance was measured at $490 \mathrm{~nm}$ on a BioTek Synergy HT Multi-Detection Microplate Reader (BioTek, Winooski, VT, USA).

Scratch assay. The cells were cultured in 6-well plates for $10 \mathrm{~h}$. Then, a 200- $\mu \mathrm{l}$ pipette tip was used to make two parallel wounds and one vertical wound per well. After being washed with PBS, the cells were incubated in serum-free medium at different doses of SFN-Cys for $24 \mathrm{~h}$. The image of the wound area was captured by a phase-contrast microscope (Leica) at 0 and $24 \mathrm{~h}$, and measured by the Image J processing program.

Invasion assay. The 24-well invasion chamber with $8-\mu \mathrm{m}$ pores coated with Matrigel matrix was used for the cell invasion assay. Matrigel matrix was diluted with FBS-free medium to $2 \mathrm{mg} / \mathrm{ml}$. The Transwell chambers were rehydrated with FBS-free medium at $37^{\circ} \mathrm{C}$ for $30 \mathrm{~min}$, and then the cells $\left(1 \times 10^{5}\right)$ were seeded in the upper chamber with $10 \%$ FBS culture medium. The $500 \mu \mathrm{l}$ of culture medium was added to the lower chambers. After incubation at different doses of SFN-Cys for $24 \mathrm{~h}$, the cells in the upper chamber were wiped off with cotton swab. The invaded cells in the lower chamber were fixed with $100 \%$ methanol for $20 \mathrm{~min}$, and subsequently stained with $0.5 \%$ crystal violet solution for $20 \mathrm{~min}$. Then, the cells were rinsed with distilled water and observed in five randomly selected fields per well under microscope. The ImageJ processing program was used for data analysis.

Immunoblotting. The cells were harvested and lysed with lysis buffer (Thermo Fisher Scientific, Waltham, MA, USA) for $30 \mathrm{~min}$. Then, the cell lysate was centrifuged at $12,000 \mathrm{x} \mathrm{g}$ for $10 \mathrm{~min}$. The BCA protein assay kit (Invitrogen) was used to detect protein concentrations. Equal amounts of protein were separated using SDS-PAGE gels and transferred to nitrocellulose membranes. The membranes were blocked with $1.5 \%$ BSA for $1 \mathrm{~h}$. After incubation with primary antibodies overnight at $4^{\circ} \mathrm{C}$, the fluorescence-labeled secondary antibody (LI-COR Biosciences, Lincoln, NE, USA) was incubated with the membranes. After being washed, the protein bands were detected using the Odyssey Infrared Imaging System (LI-COR Biosciences). $\beta$-actin was used as an internal control.

Immunofluorescence assays. The cells $\left(4 \times 10^{4}\right)$ were seeded in a 24-well with glass coverslips and incubated for $10 \mathrm{~h}$ at $37^{\circ} \mathrm{C}$. Following treatment with $15 \mu \mathrm{M} \mathrm{SFN}-\mathrm{Cys}$ for $24 \mathrm{~h}$, the cells were fixed with $4 \%$ paraformaldehyde for $15 \mathrm{~min}$ and permeabilized with $0.5 \%$ Triton $\mathrm{X}-100$ for $20 \mathrm{~min}$ at room temperature. After blocking through 5\% BSA for $30 \mathrm{~min}$, the cells were incubated with primary antibodies for $2 \mathrm{~h}$ and incubated with the fluorescence-labeled secondary antibody for $1 \mathrm{~h}$. The glass coverslips were stained with DAPI and examined on confocal laser scanning microscope (Olympus FV1000; Olympus Corp., Tokyo, Japan).

Statistical analysis. The results are expressed as the mean \pm SD, and analyzed using SPSS 18.0 software package by one-way ANOVA. The differences were considered statistically significant at $\mathrm{p}<0.05$. 

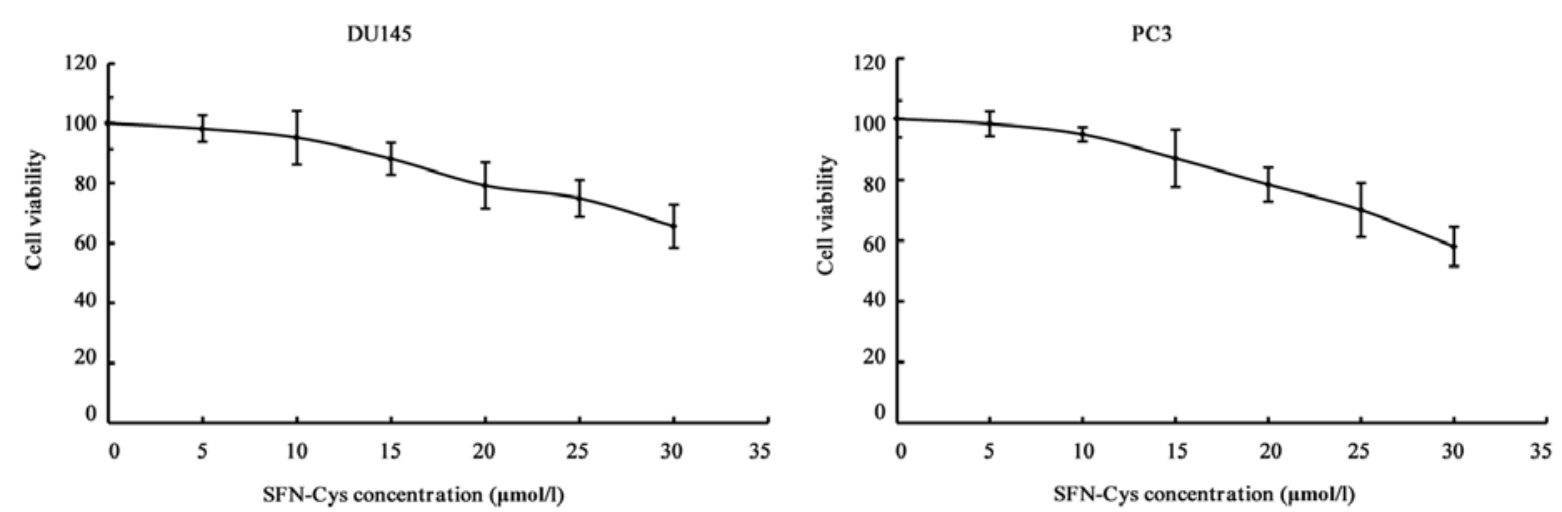

Figure 1. SFN-Cys inhibits cell proliferation. The DU145 and PC3 cells were treated with increasing concentrations of SFN-Cys for $24 \mathrm{~h}$. Cell proliferation was determined by the MTS assay. Data are presented as the percentage of the control. The results are expressed as the mean \pm SD, from three independent experiments. SFN-Cys, sulforaphane-cysteine.

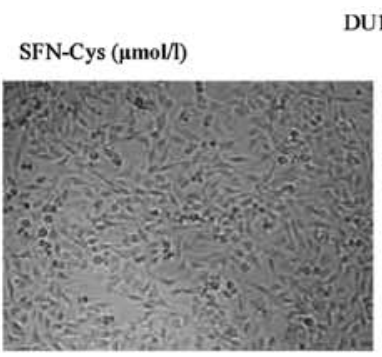

0

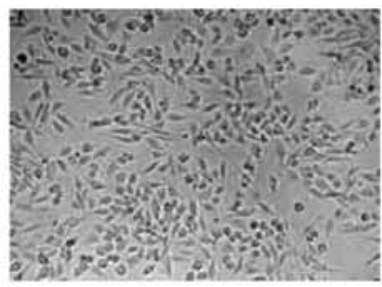

10
DU145

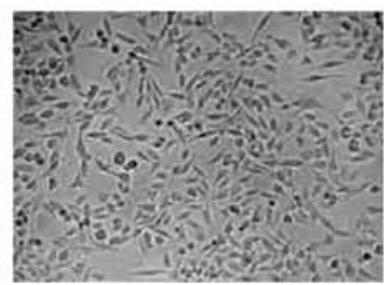

5

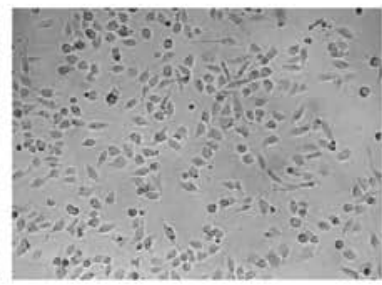

15

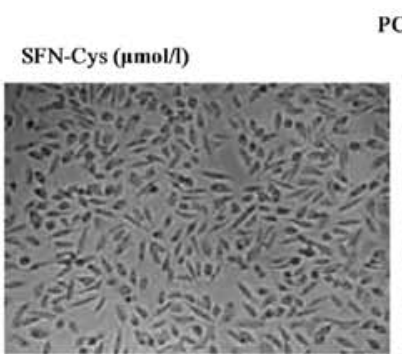

0

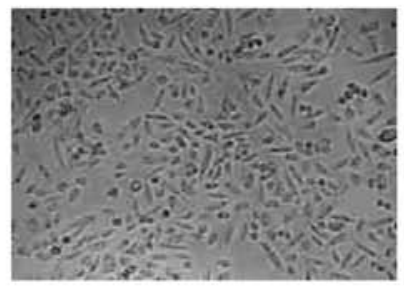

10
PC3

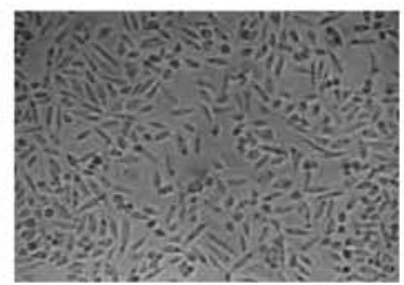

5

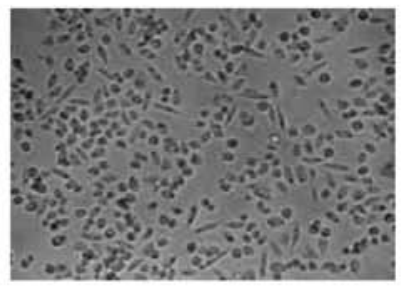

15

Figure 2. SFN-Cys induces cell morphological alterations. Compared with the control group, the DU145 and PC3 cells treated with $15 \mu \mathrm{M}$ of SFN-Cys exhibited morphological changes. The Leica DMIRB microscope was used to observe cell morphology. SFN-Cys, sulforaphane-cysteine.

\section{Results}

SFN-Cys inhibits cell proliferation. MTS assay was used to assess the effect of SFN-Cys on cell viability. The cells were treated with $0,5,10,15,20,25$ and $30 \mu \mathrm{M}$ SFN-Cys for $24 \mathrm{~h}$. The results showed that cell viability was inhibited by SFN-Cys in a concentration-dependent manner (Fig. 1). Our study showed that $20 \mu \mathrm{M}$ of SFN-Cys inhibited cell growth, but $15 \mu \mathrm{M}$ of SFN-Cys did not markedly decrease cell viability. Thus, we chose $15 \mu \mathrm{M}$ SFN-Cys as an optimal concentration for the invasion studies.

SFN-Cys induces morphological changes. Following a $24 \mathrm{~h}$ treatment with $15 \mu \mathrm{M}$ SFN-Cys, we observed obvious morphological changes in the DU145 and PC3 cells, such as cell contraction and pseudopodia shortening (Fig. 2). Because the cellular pseudopodia are closely related to tumor invasion, we speculated that SFN-Cys inhibited cell invasion in the DU145 and PC3 cells. Therefore, $15 \mu \mathrm{M}$ was the optimal concentration for the invasion studies.
SFN-Cys inhibits migration in a dose-dependent manner. We evaluated the effects of SFN-Cys on cell migration by scratch assay. After being treated with different doses of SFN-Cys, the area of the wound was observed under a microscope at 0 and $24 \mathrm{~h}$ (Fig. 3). The results showed that SFN-Cys significantly decreased cell migration when compared to the control $(0 \mu \mathrm{M})$ in the DU145 and PC 3 cells.

SFN-Cys inhibits cell invasion in the DU145 and PC3 cells. Transwell invasion assays were used to assess the effects of SFN-Cys on cell invasion. The cells were treated with different concentrations of SFN-Cys $(0,5,10$ and $15 \mu \mathrm{M})$. Then, the invaded cells were counted as described in Materials and methods. The results showed that the cell invasiveness was significantly reduced when compared to the control group in a dose-dependent manner (Fig. 4A). Meanwhile, we aimed to ascertain whether SFN-Cys inhibits invasion via ERK1/2 activation. The ERK1/2 inhibitor PD98059 $(25 \mu \mathrm{M})$ was added to the medium for $30 \mathrm{~min}$, and then the cells were treated with $15 \mu \mathrm{M}$ of SFN-Cys for $24 \mathrm{~h}$. The results showed that the 

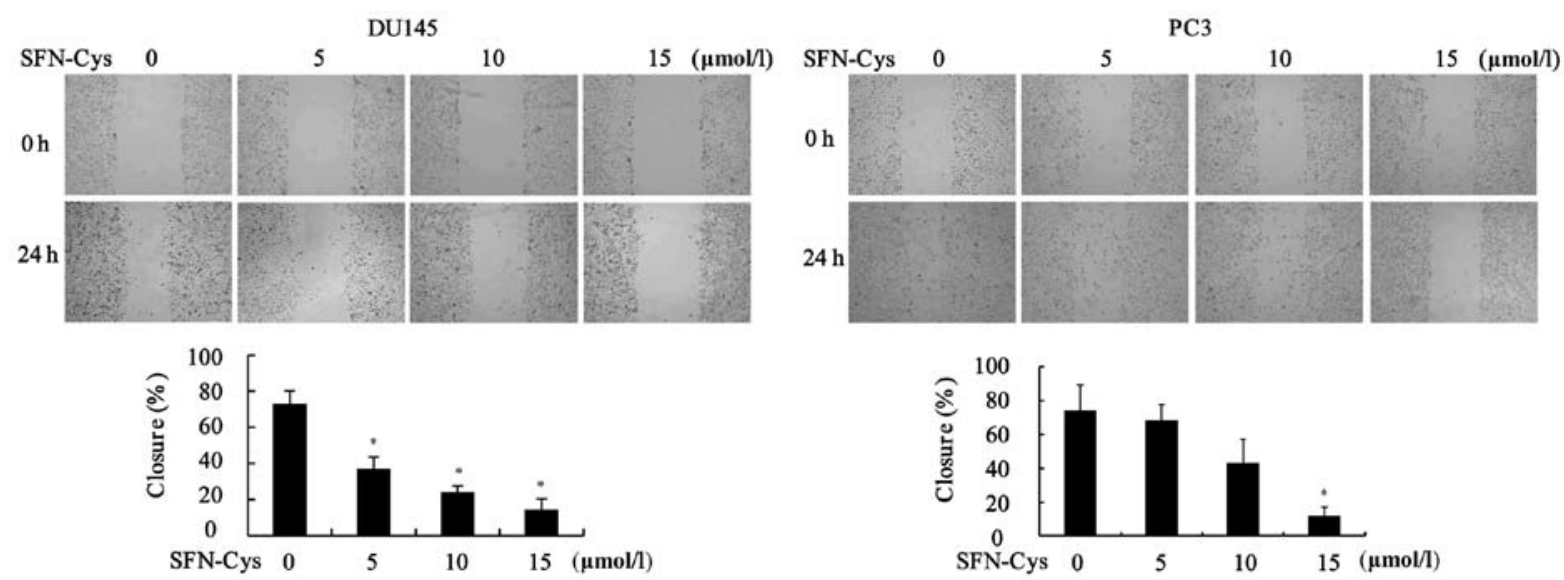

Figure 3. SFN-Cys inhibits migration in the DU145 and PC 3 cells. The cells were scratched and treated with 0,5, 10 and $15 \mu \mathrm{M}$ of SFN-Cys for $24 \mathrm{~h}$. An image of the wound closure area was captured and measured with ImageJ software. ${ }^{*} \mathrm{P}<0.05$ vs. the control, $\mathrm{n}=3$. SFN-Cys, sulforaphane-cysteine.
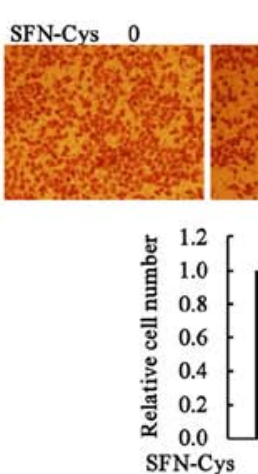

DU145
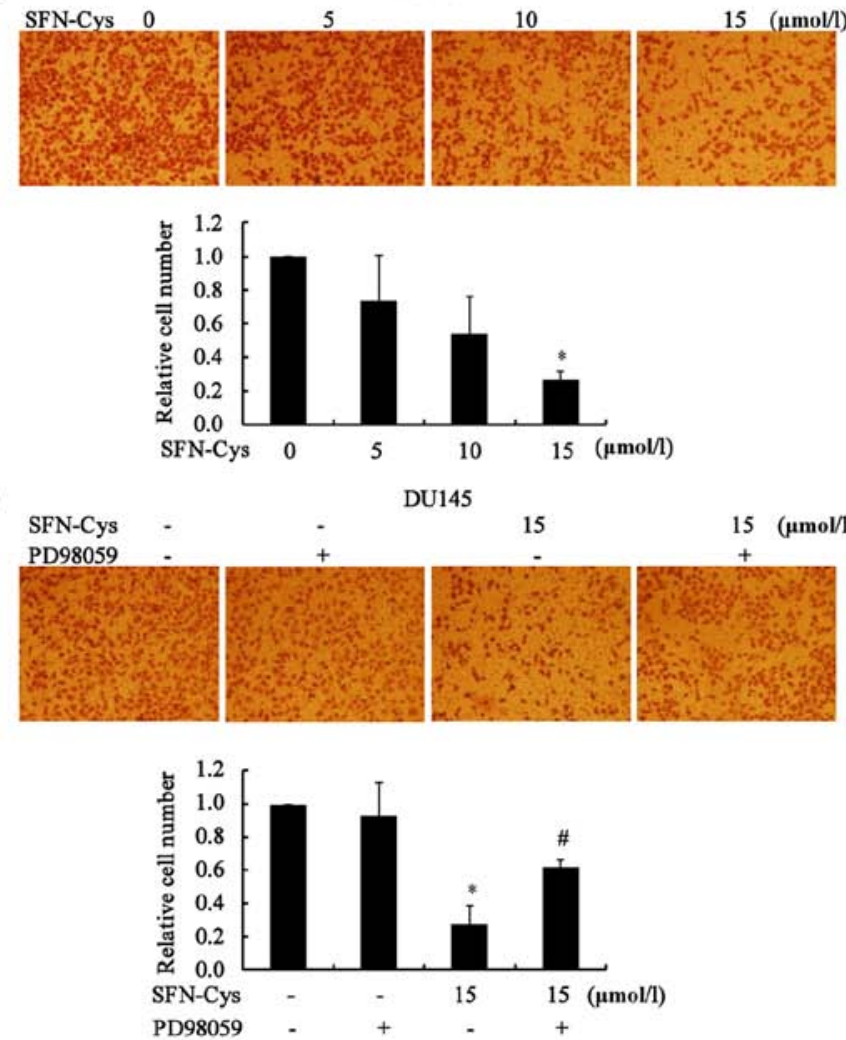
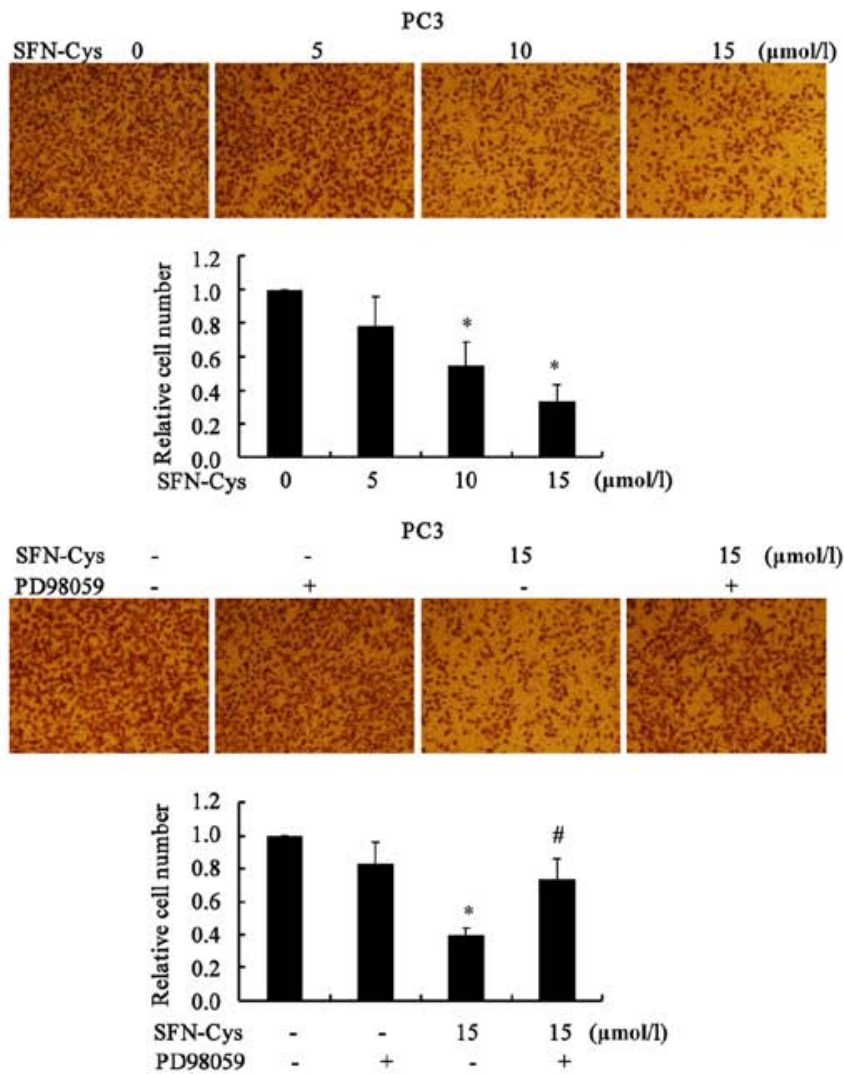

Figure 4. SFN-Cys inhibits invasion in the DU145 and PC3 cells. (A) The cells $\left(1 \times 10^{5}\right)$ were seeded in 24-well invasion chambers and treated with different doses of SFN-Cys $(0,5,10$ and $15 \mu \mathrm{M})$. (B) The cells were treated with ERK1/2 inhibitor PD98059 $(25 \mu \mathrm{M})$ for 30 min, then $15 \mu \mathrm{M}$ of SFN-Cys was added to the medium for $24 \mathrm{~h}$. The invaded cells were counted. ${ }^{*} \mathrm{P}<0.05$ vs. the control, ${ }^{*} \mathrm{p}<0.05$ vs. the SFN-Cys-only group, $\mathrm{n}=3$. SFN-Cys, sulforaphane-cysteine; ERK1/2, extracellular signal-regulated kinase 1/2.

invaded cells were significantly increased when compared to the SFN-Cys-only group in the DU145 and PC3 cells, respectively (Fig. 4B). These results suggest that SFN-Cys inhibited invasion via activation of ERK1/2 signaling in the human prostate cancer cells.

SFN-Cys inhibits cell invasion of DU145 and PC3 cells via sustained ERK1/2 phosphorylation. We further explored the molecular mechanisms involved in SFN-Cys-triggered invasion. Our previous studies showed that phosphorylation of ERK1/2 reached the highest degree at $24 \mathrm{~h}$. Therefore, we chose $24 \mathrm{~h}$ as the optimal time for subsequent study. The cells were treated with increasing doses of SFN-Cys $(0,5$, 10 and $15 \mu \mathrm{M}$ ) for $24 \mathrm{~h}$. Western blot analysis showed that phosphorylation of ERK1/2 was significantly increased at $15 \mu \mathrm{M}$ of SFN-Cys (Fig. 5). The results indicated that SFN-Cys inhibited invasion via activation of ERK1/2 in both the DU145 and PC3 cells. 

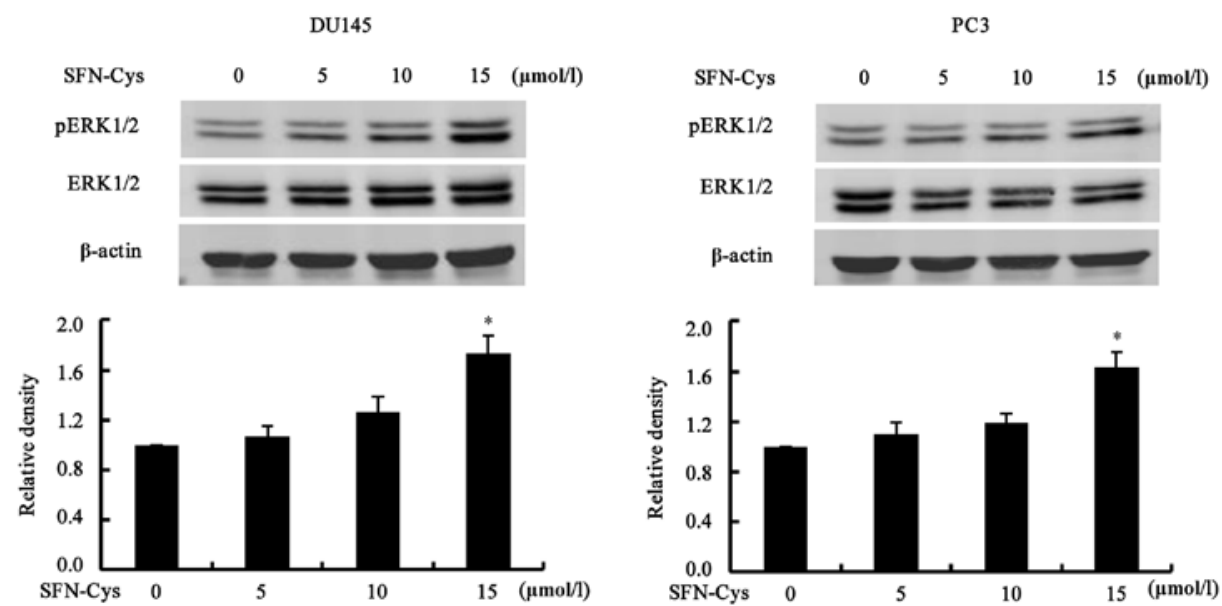

Figure 5. SFN-Cys induces persistent ERK1/2 phosphorylation. The DU145 and PC3 cells were treated with various concentrations of SFN-Cys $(0,5$, 10 and $15 \mu \mathrm{M}$ ) for $24 \mathrm{~h}$. The results showed that ERK1/2 phosphorylation was significantly increased at $15 \mu \mathrm{M}$ of SFN-Cys. ${ }^{*} \mathrm{P}<0.05$ vs. the control, $\mathrm{n}=3$. SFN-Cys, sulforaphane-cysteine; ERK1/2, extracellular signal-regulated kinase 1/2.

A

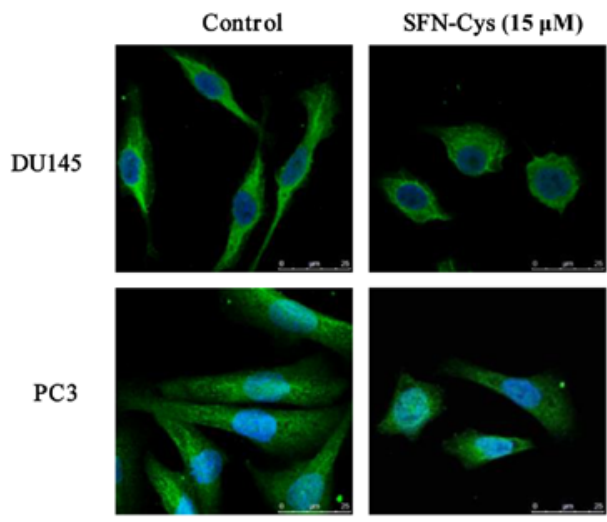

B

DU145
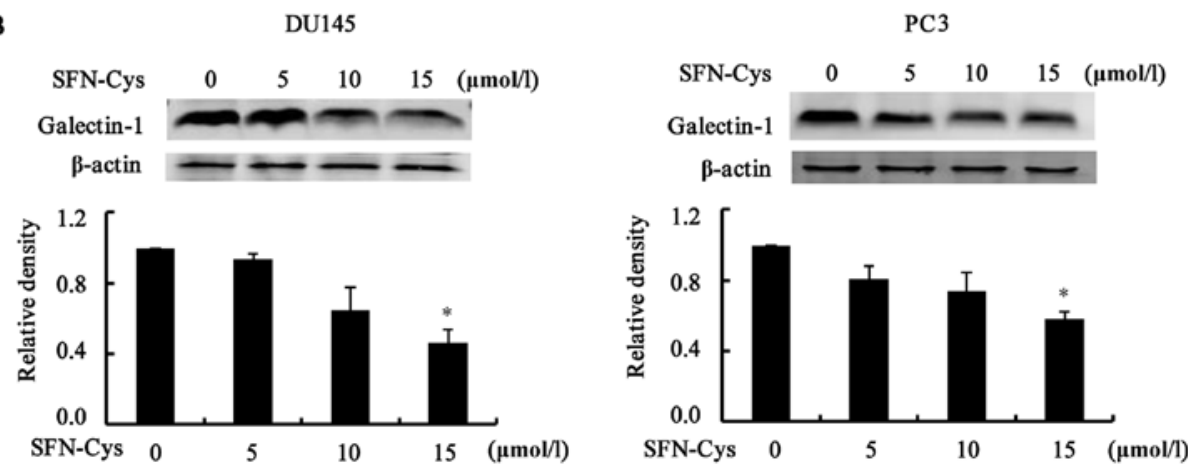

Figure 6. SFN-Cys decreases galectin-1 expression in the DU145 and PC3 cells. (A) The cells were treated with $15 \mu \mathrm{M}$ of SFN-Cys for $24 \mathrm{~h}$. Immunofluorescence showed that galectin-1 was mainly located in the cytoplasm and the cell membrane. Galectin-1 expression was downregulated in the treated cells. (B) The cells were treated with increasing doses of SFN-Cys $(0,5,10$ and $15 \mu \mathrm{M})$ for $24 \mathrm{~h}$. Western blot analysis showed that galectin-1 expression was significantly decreased in the DU145 and PC3 cells. The results are expressed as the mean \pm SD. ${ }^{*} \mathrm{P}<0.05$ vs. the control, $\mathrm{n}=3$. SFN-Cys, sulforaphane-cysteine.

SFN-Cys inhibits galectin-1-related invasion. Overexpression of galectin-1 promotes tumor cell invasion. To elucidate the mechanisms of SFN-Cys-induced invasion inhibition, we detected the expression of galectin-1 in the DU145 and PC3 cells. Immunofluorescence showed that galectin-1 was located in both the cytoplasm and the cell membrane of the prostate cancer cells. SFN-Cys $(15 \mu \mathrm{M})$ induced cellular pseudopodia shortening (Fig. 6A). Next, we used western blot analysis to examine the expression of galectin-1 protein. The results showed that the expression level of galectin-1 was markedly reduced with the increasing SFN-Cys concentrations (Fig. 6B). These results suggested that SFN-Cys inhibited invasion via downregulation of galectin-1 in the DU145 and PC3 cells.

SFN-Cys downregulates galectin-1 via activation of ERK1/2. We examined the link between ERK1/2 phosphorylation and galectin-1 expression. First, cells were treated with ERK1/2 inhibitor PD98059 $(25 \mu \mathrm{M})$ for $30 \mathrm{~min}$, then $15 \mu \mathrm{M}$ of SFN-Cys was added to the medium for $24 \mathrm{~h}$. Western blot analysis showed that phosphorylation of ERK1/2 was 

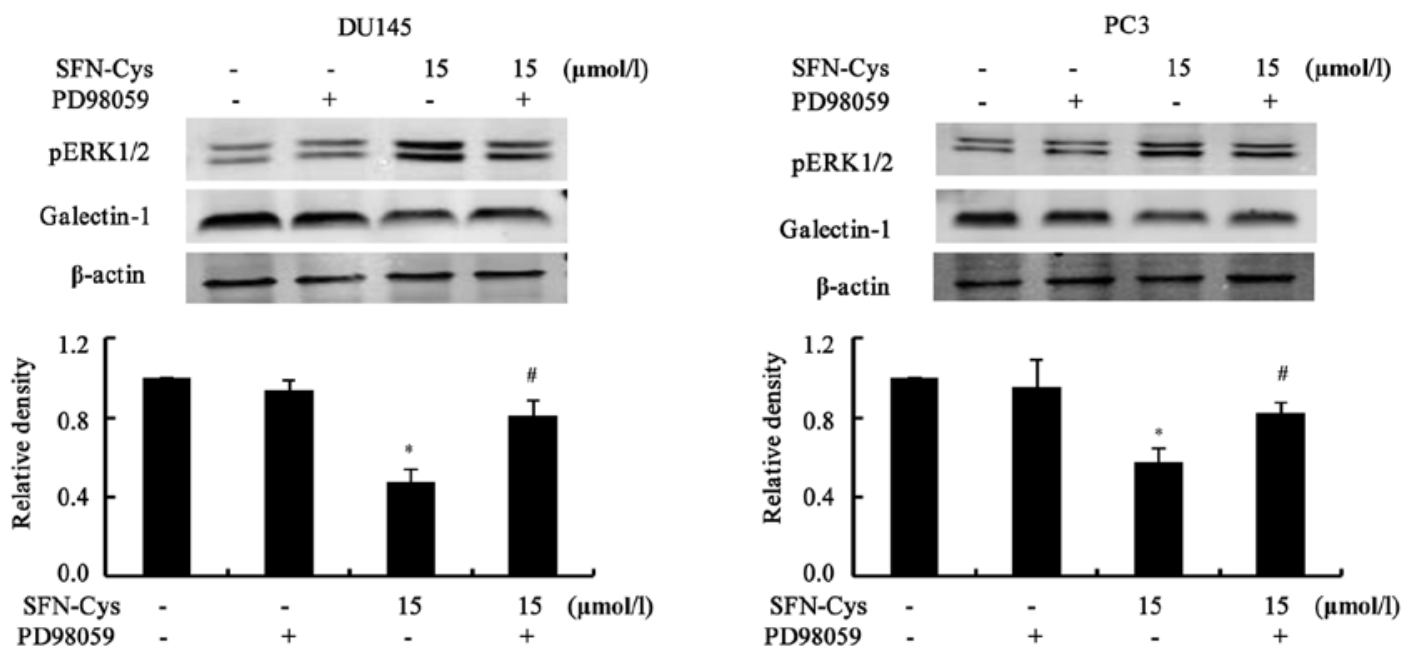

Figure 7. SFN-Cys downregulates galectin-1 via sustained ERK1/2 activation. After treatment with PD98059 (25 $\mu \mathrm{M})$ for 30 min, the cells were incubated with $15 \mu \mathrm{M}$ SFN-Cys for $24 \mathrm{~h}$. Western blot analysis showed that activation of ERK1/2 was markedly decreased compared with the SFN-Cys-only group. The downregulation of galectin-1 was reversed by PD98059. ${ }^{*} \mathrm{P}<0.05$ vs. the control, ${ }^{\#} \mathrm{p}<0.05$ vs. the SFN-Cys-only group, $\mathrm{n}=3$. SFN-Cys, sulforaphane-cysteine; ERK1/2, extracellular signal-regulated kinase $1 / 2$.

markedly reduced, but downregulation of galectin-1 was reversed by PD98059 (Fig. 7), implying that galectin-1 is the downstream effector of ERK1/2 in the DU145 and PC3 cells. All the data indicated that SFN-Cys suppressed invasion via ERK1/2-mediated downregulation of galectin-1 in the human prostate cancer cells.

\section{Discussion}

SFN suppresses invasion in a variety of tumor cells (22-24). Due to a short half-life, SFN has not been used in clinical treatment. SFN-Cys, as a major metabolite of SFN, was found to have extensive tissue distribution in treated mice and a longer half-life $(3,5)$. Therefore, it was more valuable to investigate the mechanisms involved in the inhibition of invasion in prostate cancer cells by SFN-Cys. In the present study, we found that SFN-Cys inhibited cell proliferation by MTS assay in the DU145 and PC3 cells. This provided an optimum concentration and treatment time with which to investigate invasion inhibition. Meanwhile, these data confirmed that SFN-Cys also inhibited tumor growth, which may be related to inhibition of cell proliferating signaling, such as transient activation of ERK1/2 and downstream oncoproteins. In our model, SFN-Cys triggered sustained activation of ERK1/2. These data triggered different results which include cell cycle arrest and apoptosis. More importantly, the phosphorylation of ERK1/2 also caused inhibition of invasion. We demonstrated that SFN-Cys significantly suppressed invasion in the cells following treatment with $15 \mu \mathrm{M}$ SFN-Cys by scratch and invasion assays, indicating that broccoli-derived SFN-Cys has anti-invasion potential in human prostate cancer cells.

In addition, we further explored the molecular mechanism of SFN-Cys-mediated inhibition of invasion. The ERK1/2 signaling pathway is associated with intracellular protein-protein interactions and the regulation of multiple cellular processes, such as proliferation, differentiation, invasion and apoptosis. It was reported that high expression of pERK $1 / 2$ is found in benign prostate lesions, suggesting a good prognosis (25). Moreover, activation of ERK1/2 inhibited invasion in various tumor cells. Our previous studies demonstrated that SFN inhibited invasion via persistent ERK1/2 phosphorylation in human glioblastoma cells (10) and prostate cancer cells (6). In this study, SFN-Cys significantly increased ERK1/2 phosphorylation in a dose-dependent manner, and effectively inhibited invasion in the DU145 and PC3 cells, which could be blocked by PD98059. These results indicated that SFN-Cys inhibited tumor invasion through sustained ERK1/2 activation in human prostate cancer cells.

Tumor invasion is a complex process, including adhesion and degradation of ECM, angiogenesis, and proliferation. Galectin-1 contributes to cell-to-ECM adhesion and migration (26). Studies have shown that galectin-1 promoted tumor invasion in oral cancer and lung adenocarcinoma (19). It was reported that galectin-1 expression is significantly correlated with tumor stage (27) and clinical prognosis (28). Our results showed that SFN-Cys markedly downregulated galectin-1 levels in the DU145 and PC3 cells. When the cells were treated with PD98059 and SFN-Cys, the downregulation of galectin-1 was reversed by PD98059. The immunofluorescence assays showed that galectin-1 was mainly located in the cytoplasm and the cell membrane of prostate cancer cells. These results demonstrated that SFN-Cys downregulated galectin-1 via sustained ERK1/2 phosphorylation in human prostate cancer cells. The question is how does ERK1/2 phosphorylation lead to galectin-1 downregulation? Studies have shown that some transcription factors modulate galectin-1 expression such as hypoxia inducible factor-1 (29) and activator protein-1 (30); several transcription factors function by ERK 1/2 phosphorylation $(31,32)$. Therefore, we aimed to ascertain that SFN-Cys may downregulate galectin-1 via ERK1/2-relevant transcription factors, such as AP-1 and Egr-1. Galectin-1 was confirmed to promote cell migration and invasiveness, which were found to be major hallmarks in tumor progression. Cell migration occurs through multiple adhesion and spreading events, especially the degradation of ECM proteins by serine proteases, cathepsins, and matrix metalloproteinases (MMPs) such as 
MMP-2, MMP-9 and MMP-14. As a result, the proteasome pathway may be a major player in the regulation of galectin-1 and tumor invasion; however further studies are needed.

Galectin-1, as a glycoprotein, plays roles in the cell membrane and the ECM. The carbohydrate chains of galectin-1 could interact with adhesion molecules, such as integrin and E-cadherin, on cell surfaces and in the ECM, regulating subsequent motility and adhesion (33). Studies have shown that galectin-1 stimulated collagen, fibronectin synthesis and laminin expression $(16,34)$ that promoted cell-matrix adhesion. Furthermore, galectin-1 induced epithelial-to-mesenchymal transition (EMT) and upregulated integrins that mediated cell-ECM interactions (35). Upregulated galectin-1 was found to stimulate platelets to release angiogenesis-related factors (36). Furthermore, galectin-1 overexpression was found to cause chemoresistance and promoted carcinogenesis and invasion (37). In the present study, SFN-Cys significantly decreased galectin-1 expression, indicating that the use of SFN-Cys possesses a better chemotherapeutic effect. Meanwhile, SFN-Cys is absorbed and maintains appropriate blood and tissue concentrations (5), which suggests that SFN-Cys shows promise as an anticancer agent for clinical trial.

In summary, our results revealed that SFN-Cys inhibited invasion in human prostate cancer cells via persistent ERK1/2 phosphorylation which triggers galectin-1 downregulation. This study demonstrated that SFN-Cys has potential as an anticancer agent for prostate cancer therapy.

\section{Acknowledgements}

The present study was supported by the National Natural Science Foundation of China (grant no. 81272843).

\section{References}

1. Abdull Razis AF and Noor NM: Cruciferous vegetables: Dietary phytochemicals for cancer prevention. Asian Pac J Cancer Prev 14: 1565-1570, 2013.

2. Lenzi M, Fimognari $C$ and Hrelia P: Sulforaphane as a promising molecule for fighting cancer. Cancer Treat Res 159: 207-223, 2014.

3. Clarke JD, Hsu A, Williams DE, Dashwood RH, Stevens JF, Yamamoto $M$ and Ho E: Metabolism and tissue distribution of sulforaphane in Nrf2 knockout and wild-type mice. Pharm Res 28: 3171-3179, 2011.

4. Myzak MC, Karplus PA, Chung FL and Dashwood RH: A novel mechanism of chemoprotection by sulforaphane: Inhibition of histone deacetylase. Cancer Res 64: 5767-5774, 2004.

5. Gasper AV, Al-Janobi A, Smith JA, Bacon JR, Fortun P Atherton C, Taylor MA, Hawkey CJ, Barrett DA and Mithen RF: Glutathione S-transferase M1 polymorphism and metabolism of sulforaphane from standard and high-glucosinolate broccoli. Am J Clin Nutr 82: 1283-1291, 2005.

6. Peng X, Zhou Y, Tian H, Yang G, Li C, Geng Y, Wu S and Wu W: Sulforaphane inhibits invasion by phosphorylating ERK1/2 to regulate E-cadherin and CD44v6 in human prostate cancer DU145 cells. Oncol Rep 34: 1565-1572, 2015.

7. Futran AS, Link AJ, Seger R and Shvartsman SY: ERK as a model for systems biology of enzyme kinetics in cells. Curr Biol 23: R972-R979, 2013.

8. Goulet AC, Chigbrow M, Frisk P and Nelson MA: Selenomethionine induces sustained ERK phosphorylation leading to cell-cycle arrest in human colon cancer cells. Carcinogenesis 26: 109-117, 2005.

9. Krishna-Subramanian S, Hanski ML, Loddenkemper C, Choudhary B, Pagès G, Zeitz $M$ and Hanski C: UDCA slows down intestinal cell proliferation by inducing high and sustained ERK phosphorylation. Int J Cancer 130: 2771-2782, 2012.
10. Li C, Zhou Y, Peng X, Du L, Tian H, Yang G, Niu J and Wu W: Sulforaphane inhibits invasion via activating ERK1/2 signaling in human glioblastoma U87MG and U373MG cells. PLoS One 9: e90520, 2014

11. Yang TY, Chang GC, Chen KC, Hung HW, Hsu KH, Sheu GT and Hsu SL: Sustained activation of ERK and Cdk2/cyclin-A signaling pathway by pemetrexed leading to S-phase arrest and apoptosis in human non-small cell lung cancer A549 cells. Eur J Pharmacol 663: 17-26, 2011.

12. Thomas W, Coen N, Faherty S, Flatharta CO and Harvey BJ: Estrogen induces phospholipase A2 activation through ERK1/2 to mobilize intracellular calcium in MCF-7 cells. Steroids 71: 256-265, 2006.

13. Liu Z, Yu X and Shaikh ZA: Rapid activation of ERK1/2 and AKT in human breast cancer cells by cadmium. Toxicol Appl Pharmacol 228: 286-294, 2008.

14. Bacigalupo ML, Manzi M, Rabinovich GA and Troncoso MF: Hierarchical and selective roles of galectins in hepatocarcinogenesis, liver fibrosis and inflammation of hepatocellular carcinoma. World J Gastroenterol 19: 8831-8849, 2013.

15. Tang D, Zhang J, Yuan Z, Gao J, Wang S, Ye N, Li P, Gao S, Miao Y, Wang D, et al: Pancreatic satellite cells derived galectin-1 increase the progression and less survival of pancreatic ductal adenocarcinoma. PLoS One 9: e90476, 2014.

16. Wu MH, Hong HC, Hong TM, Chiang WF, Jin YT and Chen YL: Targeting galectin-1 in carcinoma-associated fibroblasts inhibits oral squamous cell carcinoma metastasis by downregulating MCP-1/CCL2 expression. Clin Cancer Res 17: 1306-1316, 2011.

17. Kohrenhagen N, Voelker HU, Kapp M, Dietl J and Kämmerer U: The expression of galectin-1 in vulvar neoplasia. Anticancer Res 30: 1547-1552, 2010.

18. Barrow H, Rhodes JM and Yu LG: The role of galectins in colorectal cancer progression. Int J Cancer 129: 1-8, 2011.

19. Wu MH, Hong TM, Cheng HW, Pan SH, Liang YR, Hong HC, Chiang WF, Wong TY, Shieh DB, Shiau AL, et al: galectin-1-mediated tumor invasion and metastasis, up-regulated matrix metalloproteinase expression, and reorganized actin cytoskeletons. Mol Cancer Res 7: 311-318, 2009.

20. Elola MT, Wolfenstein-Todel C, Troncoso MF, Vasta GR and Rabinovich GA: Galectins: Matricellular glycan-binding proteins linking cell adhesion, migration, and survival. Cell Mol Life Sci 64: 1679-1700, 2007.

21. Fuertes MB, Molinero LL, Toscano MA, Ilarregui JM, Rubinstein N, Fainboim L, Zwirner NW and Rabinovich GA: Regulated expression of galectin-1 during T-cell activation involves Lck and Fyn kinases and signaling through MEK1/ERK, p38 MAP kinase and p70S6 kinase. Mol Cell Biochem 267: 177-185, 2004.

22. Wang L, Tian Z, Yang Q, Li H, Guan H, Shi B, Hou P and Ji M: Sulforaphane inhibits thyroid cancer cell growth and invasiveness through the reactive oxygen species-dependent pathway. Oncotarget 6: 25917-25931, 2015.

23. Mokhtari RB, Kumar S, Islam SS, Yazdanpanah M, Adeli K, Cutz E and Yeger H: Combination of carbonic anhydrase inhibitor, acetazolamide, and sulforaphane, reduces the viability and growth of bronchial carcinoid cell lines. BMC Cancer 13: 378, 2013.

24. Pastorek M, Simko V, Takacova M, Barathova M, Bartosova M, Hunakova L, Sedlakova O, Hudecova S, Krizanova O, Dequiedt F, et al: Sulforaphane reduces molecular response to hypoxia in ovarian tumor cells independently of their resistance to chemotherapy. Int J Oncol 47: 51-60, 2015.

25. Deschênes-Simard X, Gaumont-Leclerc MF, Bourdeau V, Lessard F, Moiseeva O, Forest V, Igelmann S, Mallette FA, Saba-El-Leil MK, Meloche S, et al: Tumor suppressor activity of the ERK/MAPK pathway by promoting selective protein degradation. Genes Dev 27: 900-915, 2013.

26. Fulcher JA, Hashimi ST, Levroney EL, Pang M, Gurney KB, Baum LG and Lee B: galectin-1-matured human monocyte-derived dendritic cells have enhanced migration through extracellular matrix. J Immunol 177: 216-226, 2006.

27. Kim HJ, Do IG, Jeon HK, Cho YJ, Park YA, Choi JJ, Sung CO, Lee YY, Choi CH, Kim TJ, et al: Galectin 1 expression is associated with tumor invasion and metastasis in stage IB to IIA cervical cancer. Hum Pathol 44: 62-68, 2013.

28. Chen J, Zhou SJ, Zhang Y, Zhang GQ, Zha TZ, Feng YZ and Zhang K: Clinicopathological and prognostic significance of galectin-1 and vascular endothelial growth factor expression in gastric cancer. World J Gastroenterol 19: 2073-2079, 2013. 
29. Zhao XY, Chen TT, Xia L, Guo M, Xu Y, Yue F, Jiang Y, Chen GQ and Zhao KW: Hypoxia inducible factor-1 mediates expression of galectin-1: The potential role in migration/invasion of colorectal cancer cells. Carcinogenesis 31: 1367-1375, 2010.

30. Juszczynski P, Ouyang J, Monti S, Rodig SJ, Takeyama K, Abramson J, Chen W, Kutok JL, Rabinovich GA and Shipp MA: The AP1-dependent secretion of galectin-1 by Reed Sternberg cells fosters immune privilege in classical Hodgkin lymphoma. Proc Natl Acad Sci USA 104: 13134-13139, 2007.

31. Yoon S and Seger R: The extracellular signal-regulated kinase: Multiple substrates regulate diverse cellular functions. Growth Factors 24: 21-44, 2006.

32. Hsieh YS, Chu SC, Yang SF, Chen PN, Liu YC and Lu KH: Silibinin suppresses human osteosarcoma MG-63 cell invasion by inhibiting the ERK-dependent c-Jun/AP-1 induction of MMP-2. Carcinogenesis 28: 977-987, 2007.

33. Barondes SH, Cooper DN, Gitt MA and Leffler H: galectins. Structure and function of a large family of animal lectins. J Biol Chem 269: 20807-20810, 1994.
34. Yun SP, Lee SJ, Jung YH and Han HJ: galectin-1 stimulates motility of human umbilical cord blood-derived mesenchymal stem cells by downregulation of smad $2 / 3$-dependent collagen $3 / 5$ and upregulation of NF- $\kappa \mathrm{B}$-dependent fibronectin/laminin 5 expression. Cell Death Dis 5: e1049, 2014.

35. Rizqiawan A, Tobiume K, Okui G, Yamamoto K, Shigeishi H, Ono S, Shimasue H, Takechi M, Higashikawa K and Kamata N: Autocrine galectin-1 promotes collective cell migration of squamous cell carcinoma cells through up-regulation of distinct integrins. Biochem Biophys Res Commun 441: 904-910, 2013.

36. Etulain J, Negrotto S, Tribulatti MV, Croci DO, Carabelli J, Campetella O, Rabinovich GA and Schattner M: Control of angiogenesis by galectins involves the release of platelet-derived proangiogenic factors. PLoS One 9: e96402, 2014.

37. Le Mercier M, Lefranc F, Mijatovic T, Debeir O, Haibe-Kains B, Bontempi G, Decaestecker C, Kiss R and Mathieu V: Evidence of galectin-1 involvement in glioma chemoresistance. Toxicol Appl Pharmacol 229: 172-183, 2008. 